\title{
Parametric Analysis of PCM Thermal Storage System in an Annual Period
}

\author{
Eneja Osterman* - Vincenc Butala - Uroš Stritih \\ University of Ljubljana, Faculty of Mechanical Engineering, Slovenia
}

Using thermal energy storage (TES) in phase change materials (PCMs) can reduce energy consumption in buildings. In summer, cold can be stored at night and released during the daytime therefore reducing the temperature while in winter, the system can be connected to a solar air collector that supplies heat. This article presents a paraffin based thermal storage unit and its annual operation. A 2D model is set up in Fluent, thereby calculating the thermal response of the unit. The cooling and heating modes along with a numerical analysis of different parameters are considered and the best ones are determined for the city of Ljubljana.

Keywords: thermal energy storage with plates, PCM, heating and cooling, parametrical analysis, annual evaluation

Highlights
- Melting temperature has significant impact on the performance of the PCM storage unit on an annual basis.
- $\quad$ larger volume flow rate of air is not necessary, due to higher fan energy consumption.
- $\quad$ A best set of parameters is given. Annual savings with the suggested configuration of parameters are $189 \mathrm{kWh}$.

\section{INTRODUCTION}

One of the priorities of the EU is to minimize the energy consumed by buildings, as stated in the EPB Directive [1]. According to the directive, alternative solutions for heating and cooling should be preferred. One very promising technology that contributes to achieving this goal is latent thermal energy storage with phase change materials (PCM). The literature on this topic shows a variety of approaches as summarized in the papers written by Farid et al. [2] the latent heat storage method provides much higher storage density, with a smaller temperature difference between storing and releasing heat. This paper reviews previous work on latent heat storage and provides an insight to recent efforts to develop new classes of phase change materials (PCMs, Soares et al. [3], Zhang et al. [4] and Osterman et al. [5].

This article presents the idea of utilizing natural sources within a stand-alone active system and focuses on two principles: one for cooling and the other one for heating. For cooling needs in summer, the idea is to store outdoor cold during the night and supply it to the indoor environment during the day. This type of cooling is suitable for climates where the diurnal temperature range is at least $15 \mathrm{~K}$ [5]. For the heating requirement, energy from the sun can be exploited in conjunction with solar air collectors [6] and [7]. It often happens that heating during the day is not neededSince due to high energy gains. Since heating load increases after sunset, day-cycle TES can be advantageously used. When the available energy exceeds the energy demand, energy is stored and later released to completely or partially replace conventional systems.

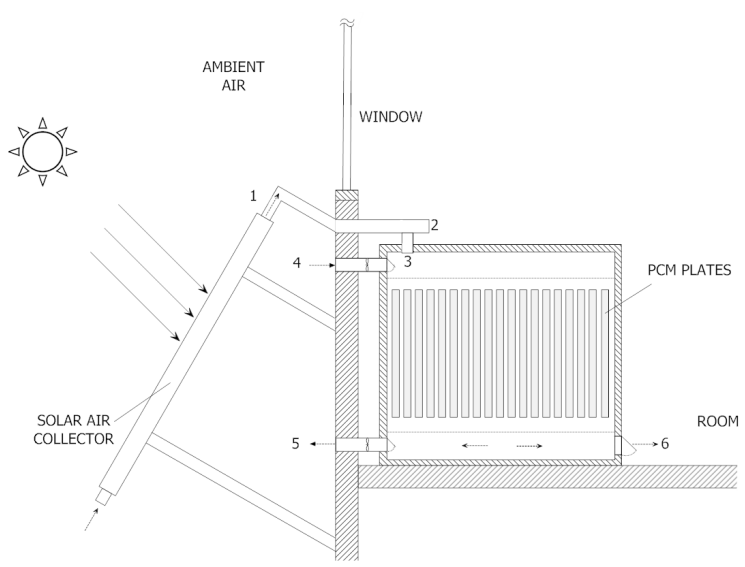

Fig. 1. Conceptual design of a storage unit

Even though previous studies have dealt with this topic [8] to [10], a key limitation was that they mainly addressed the operation of TES for either heating or cooling, but none of the studies proposed a system that would unite these two options. With our concept (Fig. 1) it would be possible to further improve output of the TES unit and utilize low exergy sources throughout the year. Moreover, research carried out so far has mainly focused on a single thermal response of TES and parametrical analyses [11] and [12] were carried out only in conjunction with it.

The main objective of this article is to analyze the annual operation of paraffin based TES, to examine 


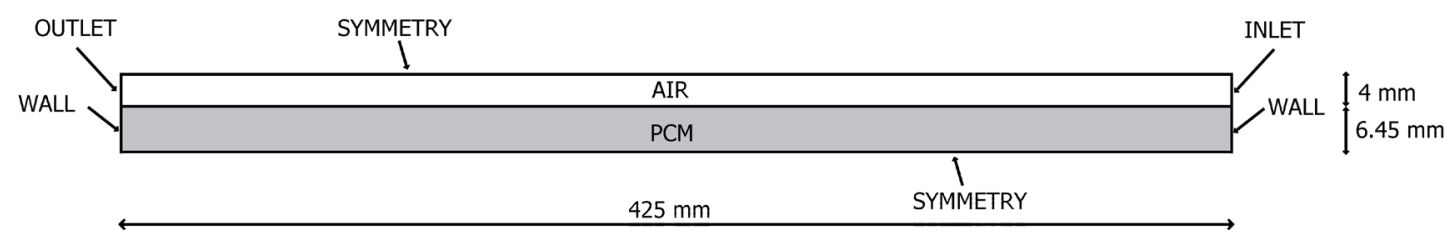

Fig. 2. Scheme of a numerical domain

whether it is feasible to use it in buildings for both heating and cooling and to carry out parametrical analysis to reveal the best set of parameters (such as geometry, air flow rate, melting point). The majority of studies focus on the thermal response of such kind of system to a step function, but very few articles [13] to [15] regardless the temperature at the intake. Warm air (during a day are accessible that examine the system over several days or even months. None of them addresses parametrical study on an annual basis. Deeper investigation and finding the best parameters is very important because it is the only clear-cut way to realistically assess the performance of TES in buildings and to make the most out of it.

In the first part of the article, a numerical CFD model and experimental setup are presented, then a comparison between the two is given and lastly novelty, i.e. influences of different parameters on TES performance, is discussed.

\section{METHODS}

\subsection{Numerical Model}

In the numerical model two modes of heat transfer are investigated. One is from air to PCM and the other one is heat conduction within PCM. Temperature and flow distribution are calculated with Fluent, which uses a finite volume method.

Since there is minor variation in the z-direction, we can assume that we are dealing with a $2 \mathrm{D}$ problem [16]. Next, not all the plates need to be modeled, because of the uniformity of the flow, so only one is considered. In the model, the domain is reduced even further to half plate and half air channel due to symmetry. The scheme of a numerical domain with dimensions is shown in Fig. 2.

\subsubsection{Governing Equations}

If we want to mathematically define the mechanisms within TES, then several assumptions for the air and PCM need to be taken into account and they can be found in Osterman et al. [6].
Equations governing the flow in the steady state are solved only for the air and two equations governing the flow in the unsteady state are applied to the entire computational domain (PCM and air). Mass, momentum and energy conservation are calculated with 2D equations as shown in Eqs. (1) to (3), where $\mathrm{S}$ stands for source term (which can include the heat of chemical reaction, and any other volumetric heat sources).

$$
\begin{gathered}
\frac{\partial v_{x}}{\partial x}+\frac{\partial v_{y}}{\partial y}=0 \\
\rho\left(v_{x} \frac{\partial v_{x}}{\partial x}+v_{y} \frac{\partial v_{x}}{\partial y}\right)=-\frac{\partial p}{\partial x}+\mu\left(\frac{\partial^{2} v_{x}}{\partial x^{2}}+\frac{\partial^{2} v_{x}}{\partial y^{2}}\right), \\
\rho\left(v_{x} \frac{\partial v_{y}}{\partial x}+v_{y} \frac{\partial v_{y}}{\partial y}\right)=-\frac{\partial p}{\partial y}+\mu\left(\frac{\partial^{2} v_{y}}{\partial x^{2}}+\frac{\partial^{2} v_{y}}{\partial y^{2}}\right), \\
\rho c_{p}\left(\frac{\partial T_{a}}{\partial t}+\vec{v} \cdot \nabla T_{a}\right)=k_{a} \nabla^{2} T_{a}+S, \\
\rho_{P C M} c_{p, P C M, a p p} \frac{\partial T_{P C M}}{\partial t}=k_{P C M} \nabla^{2} T_{P C M} .
\end{gathered}
$$

As there is no convection in PCM, only an unsteady energy equation is being solved (Eq. (4)). Phase change is taken into account via apparent specific heat (presented in Fig. 3 with a solid cyan curve).

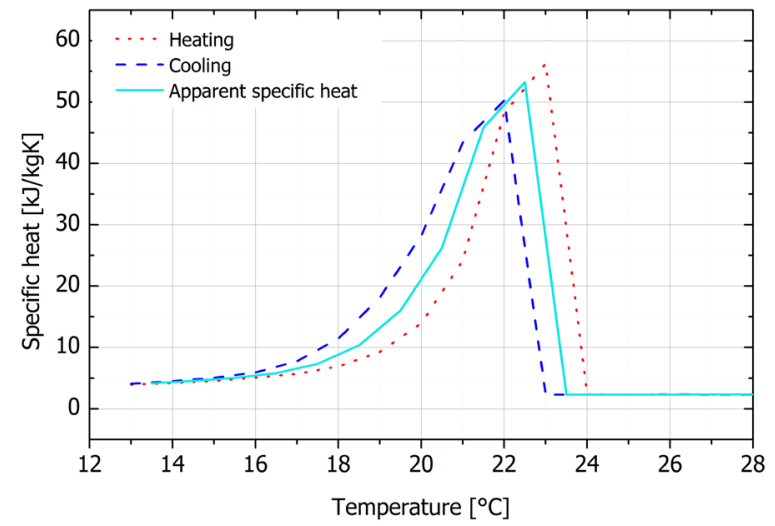

Fig. 3. Measured and apparent specific heat of RT22HC

Outlet air temperature is calculated using the presented equations and this consequently yields the 
thermal response of the PCM unit. The aim of the unit is a reduction in energy consumption, so we primarily need to investigate thermal power (Eq. (5)) and levels of stored heat/cold.

$$
P=\frac{\partial Q}{d t}=q_{m, a} c_{p, a}\left(T_{a, o u t}-T_{a, \text { in }}\right) .
$$

The thermal properties of air and PCM are presented in Table 1, more on numerical modeling can be found in [6].

Table 1. Thermal properties of air and PCM

\begin{tabular}{lcccc}
\hline & $\rho\left[\mathrm{kg} / \mathrm{m}^{3}\right]$ & $k[\mathrm{~W} /(\mathrm{mK})]$ & $c_{p}[\mathrm{~J} /(\mathrm{kgK})]$ & $\mu[\mathrm{kg} / \mathrm{ms}]$ \\
\hline Air & 1.1 & 0.024 & 1005 & $1.789 \cdot 10^{-5}$ \\
\hline RT22HC & 677 & 0.18 & curve & $/$ \\
\hline
\end{tabular}

\subsection{Experimental Work}

In order to validate the numerical model, a test rig for measuring the thermal response of the PCM unit was constructed. The casing was made of $0.8 \mathrm{~cm}$ thick PMMA and the external dimensions were $77 \mathrm{~cm} \times 67 \mathrm{~cm} \times 42 \mathrm{~cm}$. The storage unit was insulated with $8 \mathrm{~cm}$ thick EPS. The unit contained 15 or 30 CSM (compact storage module) plates (depending on the case) filled with paraffin RT22HC [17]. The air gap between plates was $0.8 \mathrm{~cm}$.

The outer dimensions of the plates were $30 \mathrm{~cm} \times 45 \mathrm{~cm} \times 1.5 \mathrm{~cm}$ and they were vertically positioned in the storage tank. The dimensions that were used in the model were slightly different $(27 \mathrm{~cm} \times 42.5 \mathrm{~cm} \times 1.29 \mathrm{~cm})$ because plates contain less PCM due to rounding and an uneven surface.

Analyses of PCM's specific heat dependence on the temperature (DSC step and T-history measurements), thermal conductivity and density were performed in order to gain data needed for the numerical model. A detailed description and results of experimental work can be found in Osterman et al. [18].

\subsection{Principle of Annual Operation}

The heat storage unit is operating the whole year round, so two modes of operation need to be distinguished, i.e. cooling in summer and heating in winter. Ljubljana, Slovenia was taken as a reference city (but this could be done for any other location as well, hourly data needed) for which it is assumed that the heating season lasts from October to April and in the rest of the year, the building needs to be cooled. Simulating whole months would be too time consuming, so only the first week of the month was simulated. The model works in such a way that when specified conditions are met it charges/discharges the unit or it is in stand-by. In winter a solar air collector is added to the system so the air temperature from the collector $\left(T_{a, c o l}\right)$ needs to be considered as well. The principle of annual operation is precisely described in Osterman et al. [6]. All these conditions were taken into account in Fluent via a script written in Scheme. The logic was to execute 3 calculations. First, the velocity field for minimum airflow was calculated and written to a file, then the velocity field for maximum air flow was calculated and written to another file. Both of these were steady state calculations and they were succeeded by transient simulation. This one was solving only the energy equation and is called the back applicable velocity field. The time step was $300 \mathrm{~s}$.

\subsection{Parameters for Annual Evaluation}

One of the objectives set out in the introduction was to find a set of parameters where the energy savings are the greatest. The influential parameters are air flow rate, melting temperature of PCM $\left(T_{m, \text { shift }}\right.$ means shift of $c_{p}(T)$ curve left or right in Fig. 3) and geometrical properties. Air flow rate refers to the maximum, i.e. the one that is set during charging, minimum airflow is in all cases equal to $40 \mathrm{~m} 3 / \mathrm{h}$. The length and width of plates were fixed $(0.425 \mathrm{~m}$ and $0.275 \mathrm{~m})$ and thus the length of TES. The third dimension varied between $5.0 \mathrm{~mm}$ and $15.0 \mathrm{~mm}$, whereas the air gap varied between $2.5 \mathrm{~mm}$ and $10.0 \mathrm{~mm}$. The overall width of TES was constrained to $0.6 \mathrm{~m}$, therefore we

Table 2. Properties of selected geometries

\begin{tabular}{lcccc}
\hline Geometry & $\begin{array}{c}\text { Thickness - } \\
\text { plate [mm] }\end{array}$ & $\begin{array}{c}\text { Air gap } \\
{[\mathrm{mm}]}\end{array}$ & $\begin{array}{c}\text { Number of } \\
\text { plates }\end{array}$ & $\begin{array}{c}\text { Width of } \\
\text { TES [cm] }\end{array}$ \\
\hline $50 \_25$ & 5 & 2.5 & 80 & 60 \\
\hline $75 \_25$ & 7.5 & 2.5 & 60 & 60 \\
\hline $100 \_25$ & 10 & 2.5 & 48 & 60 \\
\hline $125 \_25$ & 12.5 & 2.5 & 40 & 60 \\
\hline $150 \_25$ & 15 & 2.5 & 34 & 59.5 \\
\hline $50 \_50$ & 5 & 5 & 60 & 60 \\
\hline $75 \_50$ & 7.5 & 5 & 48 & 60 \\
\hline $100 \_50$ & 10 & 5 & 40 & 60 \\
\hline $125 \_50$ & 12.5 & 5 & 34 & 59.5 \\
\hline $75 \_75$ & 7.5 & 7.5 & 40 & 60 \\
\hline $100 \_75$ & 10 & 7.5 & 34 & 59.5 \\
\hline $125 \_75$ & 12.5 & 7.5 & 30 & 60 \\
\hline $75 \_100$ & 7.5 & 10 & 34 & 59.5 \\
\hline $100 \_100$ & 10 & 10 & 30 & 60 \\
\hline $125 \_100$ & 12.5 & 10 & 27 & 60.8 \\
\hline & & & &
\end{tabular}


can calculate the maximal number of plates that would fit inside TES. Table 2 shows the dimensions of the selected geometries, the number of plates and overall width of TES.

Chosen parameters:

- $\quad$ shift in melting temperature:

$T_{m, \text { shift }}=-4 \mathrm{~K},-2 \mathrm{~K}, 0 \mathrm{~K}$ and $2 \mathrm{~K}$,

- volume flow rate:

$q_{v, \max }=75 \mathrm{~m}^{3} / \mathrm{h}, 100 \mathrm{~m}^{3} / \mathrm{h}, 125 \mathrm{~m}^{3} / \mathrm{h}$ and $150 \mathrm{~m}^{3 / \mathrm{h}}$,

- geometry.

Table 2. Properties of selected geometries

\begin{tabular}{lcccc}
\hline Geometry & $\begin{array}{c}\text { Thickness - } \\
\text { plate [mm] }\end{array}$ & $\begin{array}{c}\text { Air gap } \\
{[\mathrm{mm}]}\end{array}$ & $\begin{array}{c}\text { Number of } \\
\text { plates }\end{array}$ & $\begin{array}{c}\text { Width of } \\
\text { TES [cm] }\end{array}$ \\
\hline $50 \_25$ & 5 & 2.5 & 80 & 60 \\
\hline $75 \_25$ & 7.5 & 2.5 & 60 & 60 \\
\hline $100 \_25$ & 10 & 2.5 & 48 & 60 \\
\hline $125 \_25$ & 12.5 & 2.5 & 40 & 60 \\
\hline $150 \_25$ & 15 & 2.5 & 34 & 59.5 \\
\hline $50 \_50$ & 5 & 5 & 60 & 60 \\
\hline $75 \_50$ & 7.5 & 5 & 48 & 60 \\
\hline $100 \_50$ & 10 & 5 & 40 & 60 \\
\hline $125 \_50$ & 12.5 & 5 & 34 & 59.5 \\
\hline $75 \_75$ & 7.5 & 7.5 & 40 & 60 \\
\hline $100 \_75$ & 10 & 7.5 & 34 & 59.5 \\
\hline $125 \_75$ & 12.5 & 7.5 & 30 & 60 \\
\hline $75 \_100$ & 7.5 & 10 & 34 & 59.5 \\
\hline $100 \_100$ & 10 & 10 & 30 & 60 \\
\hline $125 \_100$ & 12.5 & 10 & 27 & 60.8 \\
\hline
\end{tabular}

The criterion for determining the best set of parameters was the total savings $E_{\text {saving }}$ in a given period of time. They consisted of two parts (Eq. (8)); one was total stored heat in TES $E_{a c c u}$ (Eq. (6)) and the other one was the energy needed for fan operation $E_{\text {consum }}$ (Eq. (7)). In this manner heat and electricity are equated, which is not justified exergetically, but is done for the sake of estimating yearly savings.

$$
\begin{gathered}
E_{\text {accu }}=\int q_{m} c_{p, a}\left(T_{a, \text { out }}-T_{a, \text { in }}\right) d t, \\
E_{\text {consum }}=\int \frac{q_{v} \Delta p}{\eta} d t, \\
E_{\text {saving }}=E_{\text {accu }}-E_{\text {consum }} .
\end{gathered}
$$

\section{RESULTS}

\subsection{Validation of the Numerical Model}

An example of solidification is presented in Fig. 4. The measured air outlet temperature and simulation results are compared with constant inlet temperature $\left(16^{\circ} \mathrm{C}\right)$ and air flow $\left(78 \mathrm{~m}^{3} / \mathrm{h}\right)$. Different flow rates and specific heats $\left(c_{p, s h i f t}\right.$ and $T_{m \text {,shift }}$ add additional amount to the base value) were simulated and the outcome shows good agreement between the two of them. Some deviations can be seen at the end of the process, where solidification finishes faster for the simulated process. The main reason for this is a nonuniformity of air flow distribution, resulting in poorer heat transfer for some plates. For more details on validation see [6].

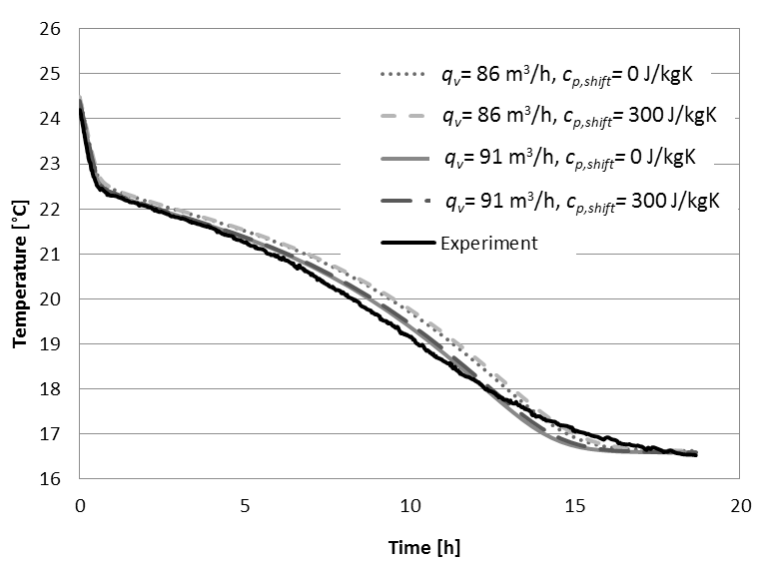

Fig. 4. Curves from experiment vs. simulations

\subsection{Annual Parametrical Analysis}

This subsection presents the results of parametrical analysis on an annual basis. Examples of temperatures in summer and winter can be found in Osterman et al. [6].

\subsubsection{Influence of Melting Temperature}

Figs. 5 and 6 show temperature in August with the melting point lowered by $4 \mathrm{~K}$ and increased by $2 \mathrm{~K}$, respectively. It can be seen that in the case of the lower melting point, the PCM doesn't reach the latent heat region because of high ambient temperatures. With a higher melting point it can be clearly seen that the air outlet temperature remains below $22{ }^{\circ} \mathrm{C}$ and TES successfully damps down temperature fluctuations. Fig. 7 shows the monthly energy savings for $100 \mathrm{~m}^{3} / \mathrm{h}$ and different melting points. In colder summer months, it is better to have a lower melting temperature, whereas in warmer months, it is better to choose a higher melting temperature. Similar observations hold true for winter. 

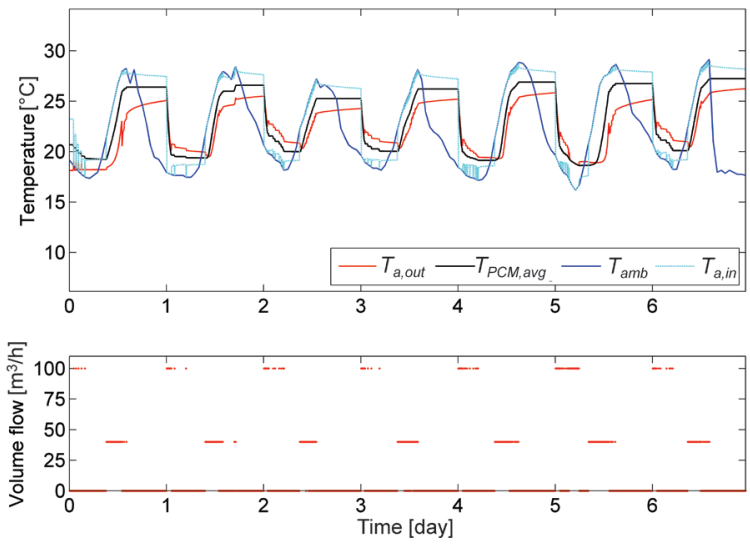

Fig. 5. Temperatures in August, $T_{m, \text { shift }}=-4 \mathrm{~K}$
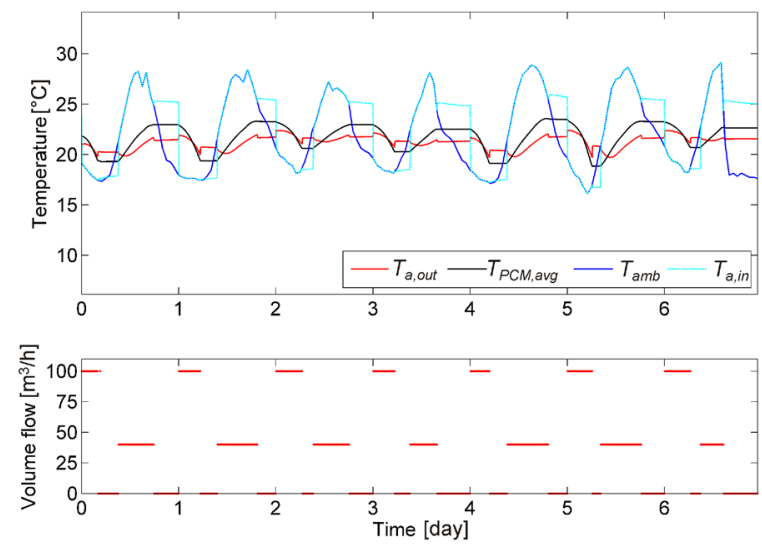

Fig. 6. Temperatures in August, $T_{m, \text { shift }}=2 \mathrm{~K}$

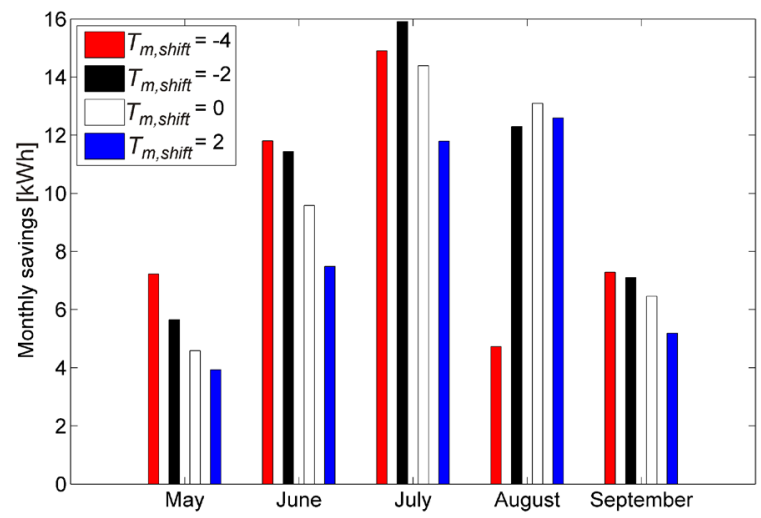

Fig. 7. Monthly energy savings for different melting temperatures

\subsubsection{Influence of Volume Flow}

A comparison of different air flow rates $\left(75 \mathrm{~m}^{3} / \mathrm{h}\right.$ and $150 \mathrm{~m}^{3} / \mathrm{h}, T_{m, \text { shift }}=0 \mathrm{~K}$ ) reveals that differences in the amount of accumulated cold in May, June and September are negligible, because of low ambient temperature. In this case increased air flow does not affect the heat transfer. Major differences occur in July and August, because of higher temperatures and only increased flow ensures that TES gets charged sufficiently.

A comparison of the electricity consumption for both flows indicates that the use of electricity to power the fan increases significantly with higher air flow. Use of electricity represents more than $30 \%$ in the case of $75 \mathrm{~m}^{3} / \mathrm{h}$, while in the case of $150 \mathrm{~m}^{3} / \mathrm{h}$, it represents more than $60 \%$. This indicates the inefficiency of larger flow rates, therefore the most suitable flow rate should be in the range between $75 \mathrm{~m}^{3} / \mathrm{h}$ and $100 \mathrm{~m}^{3} / \mathrm{h}$.

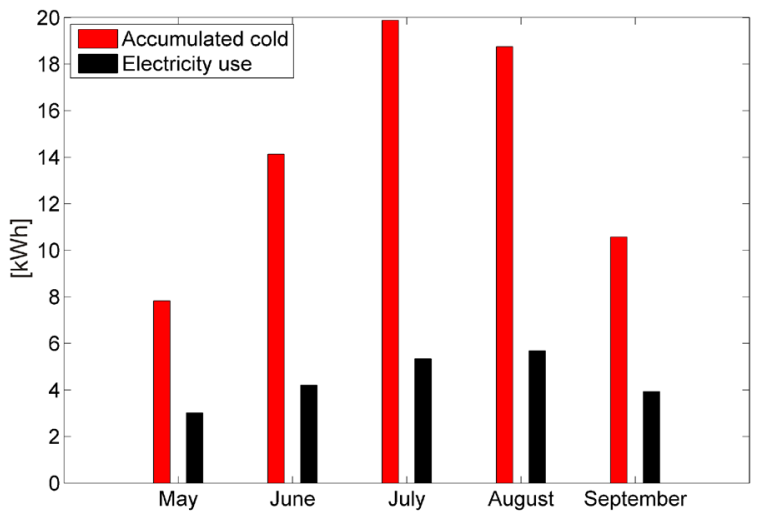

Fig. 8. Monthly accumulated cold and electricity use for $75 \mathrm{~m}^{3} / \mathrm{h}$

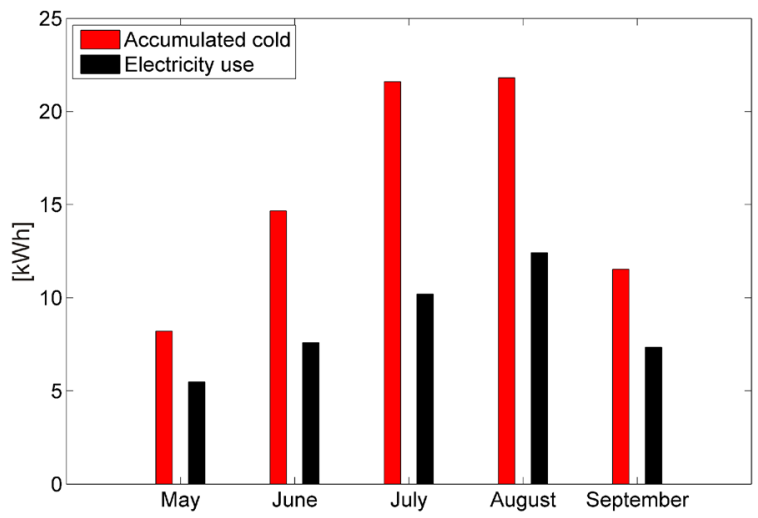

Fig. 9. Monthly accumulated cold and electricity use for $150 \mathrm{~m}^{3} / \mathrm{h}$

\subsubsection{Influence of Plate's Thickness}

The influence of the plate's thickness $(5 \mathrm{~mm}, 7.5 \mathrm{~mm}$, $10 \mathrm{~mm}, 12.5 \mathrm{~mm}$ ) was carried out for both summer and winter and for different flow rates and melting temperatures, but here we present the summer case with $100 \mathrm{~m}^{3} / \mathrm{h}$, no shift in melting temperature and for an air gap of $5 \mathrm{~mm}$. From the Fig. 10 it can be seen that the most accumulated heat is found for 
the thickest plate $(12.5 \mathrm{~mm})$, because of the largest amount of PCM in the selected TES volume.

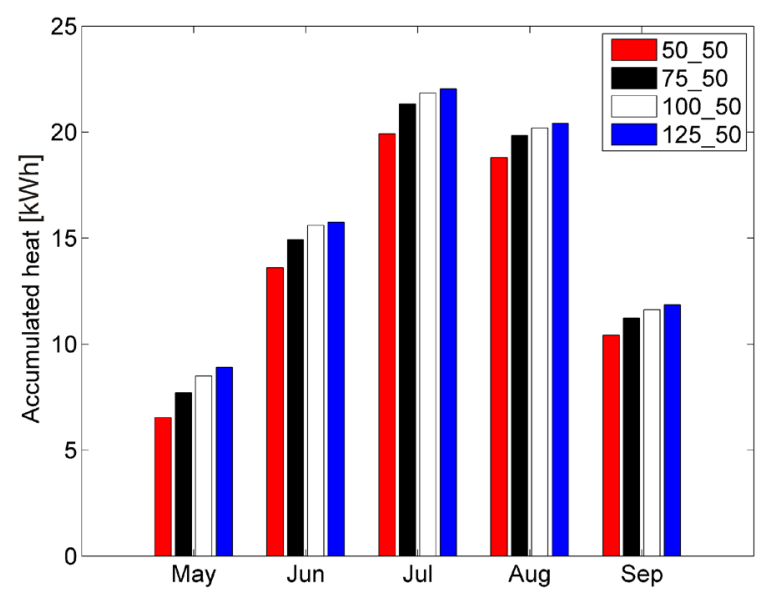

Fig. 10. Accumulated heat for different thicknesses of plates

\subsubsection{Influence of Air Gap}

A similar comparison can be carried out for different air gaps $(2.5 \mathrm{~mm}, 5 \mathrm{~mm}, 7.5 \mathrm{~mm}$ and $10 \mathrm{~mm})$, assuming the same thickness of the plates $(7.5 \mathrm{~mm})$. The largest amount of heat is accumulated in the case of the smallest air gap $(2.5 \mathrm{~mm})$, because of the largest amount of PCM in the selected TES volume (Fig. 11). From these findings it can be predicted that the best geometry will be the one with a greater plate thickness and a smaller air gap.

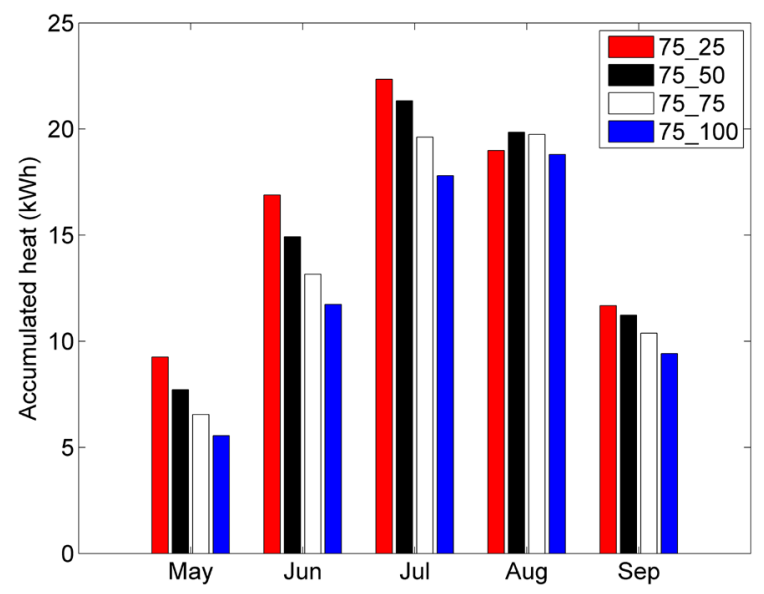

Fig. 11. Accumulated heat for different air gaps

\subsubsection{Best Set of Parameters}

In order to find the best set of parameters, simulations for all geometries, air flows and melting temperatures were carried out. Energy savings were calculated from the simulations and the results are presented in
Table 3. It turns out that the best set of parameters for Ljubljana's weather conditions is: geometry 125_25 (plate's thickness $12.5 \mathrm{~mm}$, air gap $2.5 \mathrm{~mm}$ ), volume flow $100 \mathrm{~m}^{3} / \mathrm{h}$, and shift in melting temperature -2 K. Annual savings with such a configuration are 189 $\mathrm{kWh}$. The same holds true for other geometries with the same air gap, flow rate and melting temperature.

\subsubsection{Cost of Latent Storage Unit}

The simple economic analysis presented in [6] reveals that the price for a unit of this size would be doubled compared to a conventional system. However, operational costs would be lower so we should consider TES a good alternative.

\begin{tabular}{lccc}
\hline Geometry & $T_{m, \text { shift }}[\mathrm{K}]$ & $q_{v}[\mathrm{~m} 3 / \mathrm{h}]$ & Annual savings $[\mathrm{kWh}]$ \\
\hline 125_25 & -2 & 100 & 189 \\
\hline $100 \_25$ & -2 & 100 & 188 \\
\hline $75 \_25$ & -2 & 100 & 185 \\
\hline $125 \_50$ & -2 & 100 & 177 \\
\hline $50 \_25$ & -2 & 100 & 176 \\
\hline $100 \_50$ & -2 & 100 & 176 \\
\hline $75 \_50$ & -2 & 100 & 171 \\
\hline $125 \_75$ & -2 & 100 & 163 \\
\hline $100 \_75$ & -2 & 100 & 160 \\
\hline $50 \_50$ & -2 & 100 & 159 \\
\hline $75 \_75$ & -2 & 100 & 156 \\
\hline $125 \_100$ & -2 & 100 & 148 \\
\hline $100 \_100$ & -2 & 100 & 145 \\
\hline $75 \_100$ & -2 & 100 & 139 \\
\hline
\end{tabular}

\section{CONCLUSIONS}

Numerical investigations of a latent heat storage unit for space heating and cooling, consisting of different numbers of plates filled with paraffin RT22HC, were carried out. The thermal response of TES to the temperature step function in the experiment (with 30 plates) was used for validation of the $2 \mathrm{D}$ numerical model. As there was good agreement between simulations and experimental results, the model served as a means of calculating yearly savings. The parametrical analysis showed that it is better to choose lower melting temperature in colder summer months and higher melting temperatures in warmer months higher melting temperature. Similar observations hold true for winter. The calculations reveal that larger flow rates are inefficient and therefore the most suitable flow rates are between $75 \mathrm{~m}^{3} / \mathrm{h}$ and $100 \mathrm{~m}^{3} / \mathrm{h}$. Analysis of the influence of the plate's thickness and air gap shows that the best option is a thick plate (in our case 
$12.5 \mathrm{~mm})$ and a small air gap $(2.5 \mathrm{~mm})$, because of the largest amount of PCM in the given TES volume. From the calculations, on an annual basis it turns out that the best set of parameters for Ljubljana's weather conditions is geometry 12525 (plate's thickness $12.5 \mathrm{~mm}$, air gap $2.5 \mathrm{~mm}$ ), volume flow $100 \mathrm{~m}^{3} / \mathrm{h}$, and shift in melting temperature $-2 \mathrm{~K}$. Annual savings with such a configuration are $189 \mathrm{kWh}$.

\section{NOMENCLATURE}

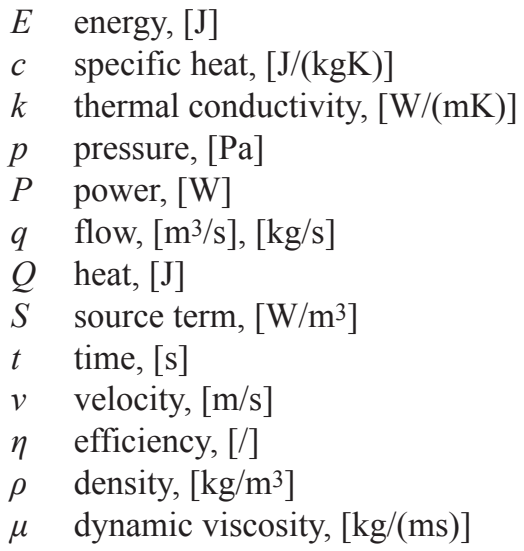

\begin{tabular}{ll}
\multicolumn{2}{l}{ Abbrevations } \\
$a$ & air \\
accu & accumulated \\
app & apparent \\
consum & consumed \\
in & inlet \\
$m$ & mass, melting \\
out & outlet \\
$v$ & volume
\end{tabular}

\section{REFERENCES}

[1] EU (2010). Directive 2010/31/EU of the European Parliament and of the Council. Official Journal of the European Union, Strasbourg.

[2] Farid, M.M., Khudhair, A.M., Razack, S.A.K., Al-Hallaj, S. (2004). A review on phase change energy storage: materials and applications. Energy Conversion and Management, vol. 45, no. 9-10, p. 1597-1615, Dol:10.1016/J. enconman.2003.09.015.

[3] Soares, N., Costa, J.., Gaspar, A.R., Santos, P. (2013). Review of passive PCM latent heat thermal energy storage systems towards buildings' energy efficiency. Energy and Buildings, vol. 59, p. 82-103, DOI:10.1016/j.enbuild.2012.12.042.

[4] Zhang, Y., Zhou, G., Lin, K., Zhang, Q., Di, H. (2007). Application of latent heat thermal energy storage in buildings: State-ofthe-art and outlook. Building and Environment, vol. 42, no. 6, p. 2197-2209, DOl:10.1016/j.buildenv.2006.07.023.

[5] Osterman, E., Tyagi, V.V., Butala, V., Rahim, N.A., Stritih, U. (2012). Review of PCM based cooling technologies for buildings. Energy and Buildings, vol. 49, p. 37-49, D0I:10.1016/j.enbuild.2012.03.022.

[6] Osterman, E., Butala, V., Stritih, U. (2015) PCM thermal storage system for 'free' heating and cooling of buildings. Energy and Buildings, vol. 106, p. 125-133, Dol:10.1016/j. enbuild.2015.04.012.

[7] Saman, W., Bruno, F., Halawa, E. (2005). Thermal performance of PCM thermal storage unit for a roof integrated solar heating system. Solar Energy, vol. 78, no. 2, p. 341-349, D0l:10.1016/j.solener.2004.08.017.

[8] Charvát, P., Klimeš, L., Ostrý, M. (2014). Numerical and experimental investigation of a PCM-based thermal storage unit for solar air systems. Energy and Buildings, vol. 68, p. 488-497, D0I:10.1016/j.enbuild.2013.10.011.

[9] Halawa, E., Saman, W. (2011). Thermal performance analysis of a phase change thermal storage unit for space heating. Renewable Energy, vol. 36, no. 1, p. 259-264, D0l:10.1016/j. renene.2010.06.029.

[10] Waqas, A., Kumar, S. (2011). Thermal performance of latent heat storage for free cooling of buildings in a dry and hot climate: An experimental study. Energy and Buildings, vol. 43, no. 10, p. 2621-2630, Dol:10.1016/j.enbuild.2011.06.015.

[11] Dolado, P., Lazaro, A., Marin, J.M., Zalba, B. (2011). Characterization of melting and solidification in a real-scale PCM-air heat exchanger: Experimental results and empirical model. Renewable Energy, vol. 36, no. 11, p. 2906-2917, D0I:10.1016/j.renene.2011.04.008.

[12] Amin, N.A.M., Belusko, M., Bruno, F., Liu, M. (2012). Optimising PCM thermal storage systems for maximum energy storage effectiveness. Solar Energy, vol. 86, no. 9, p. 2263-2272, D0I:10.1016/j.solener.2012.04.020.

[13] Gowreesunker, B.L., Tassou, S.A., Kolokotroni, M. (2013). Coupled TRNSYS-CFD simulations evaluating the performance of PCM plate heat exchangers in an airport terminal building displacement conditioning system. Building and Environment, vol. 65, p. 132-145, D0l:10.1016/j.buildenv.2013.04.003.

[14] Jaworski, M. (2014). Thermal performance of building element containing phase change material (PCM) integrated with ventilation system - An experimental study. Applied Thermal Engineering, vol. 70, no. 1, p. 665-674, Dol:10.1016/j. applthermaleng.2014.05.093.

[15] Rouault, F., Bruneau, D., Sébastian, P., Lopez, J. (2014). Experimental investigation and modelling of a low temperature PCM thermal energy exchange and storage system. Energy and Buildings, vol. 83, p. 96-107, Dol:10.1016/j. enbuild.2014.05.026.

[16] Lopez, J.P.A, Kuznik, F., Baillis, D., Virgone, J. (2013). Numerical modeling and experimental validation of a PCM to air heat exchanger. Energy and Buildings, vol. 64, p. 415-422, D0I:10.1016/j.enbuild.2013.04.017.

[17] RUBITHERM GmbH (2014). retrieved on 2014-08-07, from http://www.rubitherm.de.

[18] Osterman, E., Hagel, K., Rathgeber, C., Butala, V., Stritih, U. (2015). Parametrical analysis of latent heat and cold storage for heating and cooling of rooms. Applied Thermal Engineering, vol. 84, p. 138-149, Dol:10.1016/j. applthermaleng.2015.02.081. 